\title{
Huellas y memorias de huracanes en Hurricane Protocol de Lasana Sekou ${ }^{1}$
}

\author{
Traces and memories of hurricanes in Hurricane Protocol \\ by Lasana Sekou \\ Lucia Stecher \\ Departamento de Literatura-CECLA, Universidad de Chile \\ luciastecher@gmail.com
}

"Septiembre, agitador profesional de huracanes, avisa guerra llenando los mares de erizos y aguavivas" (11): de este modo empieza el cuento "Encancaranublado", publicado en 1982 por la escritora puertorriqueña Ana Lydia Vega. Año a año, durante lo que se conoce como la "temporada de huracanes", fuertes lluvias e intensos vientos afectan enormemente a las poblaciones del Caribe. Para el escritor cubano Miguel Barnet, "[e]l huracán es uno de los fenómenos meteorológicos de nuestra área caribeña que más incide en el desarrollo de una cultura del desastre y la resistencia" (4). Distintas formas y expresiones de la cultura popular, así como también de la producción literaria caribeña, dan cuenta del impacto de esta experiencia en la vida antillana.

1 Este artículo presenta resultados del Proyecto Fondecyt 1190607. La autora agradece también al proyecto "Connected Worlds: The Caribbean, Origin of Modern World", financiado por el programa de investigación e innovación de la Unión Europea "Horizon 2020" con el convenio Marie Sklodowska Curie No 823846. 
La temporada de huracanes en el Atlántico se extiende entre el primero de junio y el 30 de noviembre, siendo septiembre el mes que concentra la mayor cantidad de tormentas tropicales. Así ocurrió también el año 2017, en que dos huracanes de categoría 5, la más alta en términos de su poder de destrucción, golpearon al Caribe en un periodo de dos semanas. Primero fue el huracán Irma y luego el María. A su paso, dejaron pueblos y ciudades inundados, destruidos, aislados. En Chile y América Latina supimos sobre todo del impacto gigantesco del paso del María por Puerto Rico, que profundizó los problemas sociales, políticos y económicos de la isla. También recorrió el mundo la imagen de Donald Trump tirando toallas de papel a los damnificados de la isla, en cuyo auxilio acudió en forma tardía, insuficiente y despectiva, evidenciando, una vez más, que aunque los puertorriqueńos son oficialmente ciudadanos estadounidenses, el vínculo entre Estados Unidos y la isla sigue teniendo un carácter colonial. Otro huracán muy destructivo, el Katrina, que pasó por Estados Unidos en 2005 y sembró muerte y destrucción en la ciudad de Nueva Orleans, dejó claro cómo también dentro de Estados Unidos existen ciudadanos que son ignorados por el gobierno central. No es coincidencia que también en ese caso las personas negras y pobres hayan sido las más afectadas e ignoradas.

Además de Puerto Rico, muchas otras islas caribeñas sufrieron con la cruda temporada de huracanes del 2017. Entre estas se encuentran las islas de Barlovento, que forman parte de las Antillas Menores. Muy pocas noticias nos informaron sobre la devastación provocada por el Irma y el María en esos territorios. En el imaginario latinoamericano, esas islas prácticamente no existen: aunque ubicadas en el mismo mar que Cuba y Puerto Rico, parecen quedar mucho más lejos debido a lo difícil que es visitarlas y acceder a información sobre su historia, su cultura y su situación política. Las rutas aéreas se organizan según lógicas comerciales o geopolíticas, de tal modo que es mucho más caro y lento ir de Sudamérica a las Antillas Menores que a Europa. Nuestra propia historia colonial provoca que también a nivel cultural, literario e intelectual estemos infinitamente más conectados con Europa y Estados Unidos que con el Caribe e, incluso, que con el resto de América Latina.

Pese a todo, la literatura y el arte tienen la capacidad de acortar distancias históricas e imaginarias. En este ensayo, me interesa detenerme en Lasana Mwanza Sekou, un poeta e intelectual que ha jugado un rol fundamental en el surgimiento y la dinamización del sistema literario 
de la isla de San Martín. Como veremos, la editorial House of Nehesi, fundada por Sekou, le ha proporcionado a la población de la isla y de otros territorios caribeńos un espacio para publicar su producción literaria, la que además es difundida y distribuida en la región y fuera de ella. Finalmente me referiré al último libro de Sekou, Hurricane Protocol, publicado en 2019 por House of Nehesi. El poema largo homónimo aborda poéticamente el impacto de los huracanes Irma y María en la naturaleza y en las vidas de los habitantes de su isla.

Sekou nació en 1959 en Aruba, territorio del Caribe de habla holandesa. Sus padres son de San Martín, isla en la que Sekou recibió su educación escolar y a la que retornó en 1984, después de obtener un bachillerato en la Universidad Estatal de Nueva York y un magíster en la Universidad de Howard. Los críticos que se han referido a su obra literaria y editorial suelen elogiar en forma entusiasta tanto la calidad de sus textos como el impacto de su labor cultural en la vida de la isla. Así, Howard Fergus señala que "[i]t would be erroneous to say that Sekou is the literature of St. Martin, but the hyperbole is pardonable. He has featured in most of the writings as writer, inspirer, editor and pioneer publisher" $(\mathrm{X})^{2}$. En un tono similar, el crítico nigeriano establecido en San Martín, Fabian Adekunle Badejo destaca el vínculo innegable que existe entre la literatura de San Martín y la figura de Sekou: "No doubt, with firm roots in oral tradition, this nascent literature began to take a recognizable shape around the work and person of Lasana M. Sekou" (60-61)3. Acá cabría agregar que también Fabian Adekunle juega un rol muy importante al ofrecer perspectivas críticas e históricas sobre la producción literaria en la isla. En su libro Salted Tongues. Modern Literature in St. Martin, Adekunle analiza los desafíos que enfrenta la isla en sus esfuerzos por consolidar un sistema literario moderno y llama la atención sobre la importancia de expandir el público lector, consolidar los proyectos editoriales y estimular la producción de una crítica literaria que medie entre autores y lectores.

2 "No sería correcto decir que Sekou es la literatura de San Martín, pero la hipérbole es perdonable. Él ha tenido un lugar destacado en la mayor parte de los escritos, como escritor, inspirador y editor pionero" (Traducción propia).

3 "Sin duda, con raíces firmes en la tradición oral, esta literatura emergente empieza a tener una forma reconocible en torno a la obra y la persona de Lasana M. Sekou” (Traducción propia). 
“The gale DOESN't STOP AT THE FRONTIER"4: LA DIVISIÓN COLONIAL DE SAN Martín

El imperialismo y las disputas europeas por el control de las islas del Caribe han dejado en San Martín un legado particular: la división de la pequeña isla en dos territorios dependientes de dos metrópolis distintas. El sur de la isla es uno de los países constituyentes del Reino de los Países Bajos, conformado por Aruba, Curazao, San Martín y los Países Bajos. El norte es una comuna de Guadalupe, departamento de ultramar (DOM) de Francia. En total, la isla tiene 87 kilómetros cuadrados, de los que 34 corresponden al territorio del sur. En este, los idiomas oficiales son el neerlandés y el inglés; en la parte norte, el francés. Pero, en términos históricos y culturales, toda la isla configura una sola nación. La importancia del inglés y del criollo de San Martín como idioma de comunicación cotidiana y de creación musical y literaria dan cuenta de la unidad cultural de la isla. Según Adekunle, "there is no theater in Dutch or French, no musical recordings, no poetry recitals, no major cultural expressions in either of the two colonial languages..." $(6)^{5}$.

Una particularidad de San Martín con respecto a otros territorios caribeños es que su principal producto de exportación no fue la caña de azúcar sino la sal. En las primeras décadas del siglo XVII, navegantes de la Compañía de las Indias Occidentales encontraron salinas en el sur de la isla, lo que llevó a que Holanda decidiera establecer una colonia en el lugar. La sal era fundamental para la conservación de la carne y el arenque que se consumían en los viajes interoceánicos y en los territorios del Nuevo Mundo. En las salinas, que para Sekou son "the craddle of the nation" [la cuna de la nación] ("DNA"), trabajaron los hombres y mujeres arrancados de África y sometidos a la esclavitud. En su poema "Quimbé", Sekou ofrece una dura imagen de lo que significó el trabajo en las "minas" de sal:

4 Dicho de San Martín que aparece como epígrafe de Hurricane Protocol. Al señalar que "el viento no se detiene en la frontera", destaca la unidad cultural de la isla más allá de su división política.

5 "No hay teatro en holandés o francés, ni grabaciones musicales, ni recitales de poesía, ni expresiones culturales importantes en alguno de los dos idiomas coloniales" (Traducción propia). 


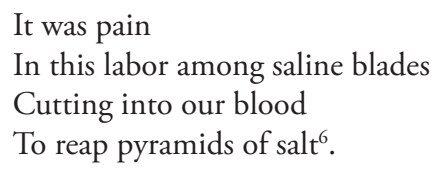

El sujeto poético habla acá desde un "nosotros" que sufre las duras condiciones del trabajo en las salinas. Para ese "nosotros" hay dolor, cristales de sal que hacen sangrar. Independientemente del producto de plantación -caña de azúcar en gran parte del Caribe, algodón en el sur de Estados Unidos, sal en San Martín, Aruba y las Islas Vírgenes, entre otras-, el denominador común para los esclavizados era el trabajo extenuante y el sufrimiento físico. La riqueza obtenida de esta labor, simbolizada en las "pirámides de sal" del poema de Sekou, era, claramente, para beneficio de otros. La explotación de las salinas terminó por agotarlas, por lo que desde 1940 en adelante, San Martín se orientó hacia el turismo como principal actividad económica (Rodríguez 136).

\section{LASAna M. Sekou: POETA Y EDITOR}

Lasana M. Sekou ha publicado trece libros de poemas, dos volúmenes de cuentos y monólogos que han sido representados en el teatro. Por la centralidad que tienen la oralidad, los neologismos y la mezcla de registros de la cultura letrada y popular, la poética de Sekou es comparable a la del barbadense Kamau Brathwaite. Para Fabian Adekunle, uno de los aspectos más notables de la poesía de Lasana M. Sekou es su "refreshing and daring use of language" (20) ${ }^{7}$. Aunque escribe principalmente en inglés, en sus poemas encontramos palabras en castellano, francés, papiamento, holandés y el creole hablado en San Martín. La diversidad lingüística de su isla, en la que pueden oírse prácticamente todos los idiomas del Caribe, es incorporada a la producción poética de Sekou. Pensados también como performance, sus poemas buscan transmitir, en sus versiones escritas, la fuerza de la oralidad: vocales alargadas, mayúsculas que marcan énfasis, cambios en la tipografía, disposición de los versos en distintas alturas de la página y frecuente presencia de neologismos.

6 "Había dolor/ en este trabajo entre cuchillas de sal/ que penetraban hasta nuestra sangre/ para cosechar pirámides de sal" (Traducción propia).

7 "Su uso refrescante y atrevido del lenguaje" (Traducción propia). 
Las tradiciones orales y la cultura popular de San Martín tienen un lugar prominente en la obra de Sekou, que actualiza los vínculos históricos y culturales pancaribeños y panafricanos. La historia de la trata y el colonialismo es revisitada críticamente por este poeta, que para el crítico Howard Fergus es "a poet of protest and revolution" $(\mathrm{XI})^{8}$. Sus principales críticas se dirigen al imperialismo, que luego de diezmar a la población nativa del Caribe, arrancó de África a millones de personas que fueron sometidas a la esclavitud para enriquecer a las metrópolis europeas. Probablemente el poema largo que mejor ilustra el compromiso de Sekou con la historia de la diáspora africana sea Nativity/ Nativité/Natividad. En él, la voz poética recorre la historia de la Maafa o tráfico transatlántico de esclavos y da cuenta de sus consecuencias en la configuración de las culturas afrodescendientes del Nuevo Mundo. A la vez que denuncia la brutalidad del saqueo de África por las metrópolis europeas y la violencia impuesta a los esclavizados llevados a alguna colonia del Nuevo Mundo, el hablante destaca el surgimiento de una cultura de resistencia y la capacidad humana de crear, trabajar y amar aún en las circunstancias más adversas. Los primeros versos del poema dan cuenta de esta "lectura dialéctica de la trata transatlántica de esclavos y sus secuelas" (Cooper 106) y de cómo, pese a los orígenes violentos de la presencia africana en el Nuevo Mundo, es posible (y necesario) desarrollar una cultura propia, resiliente y creativa:

\section{La cultura es trabajo}

y la cultura obrera se manifiesta

en amor

y verdad en laborioso

nacimiento

aunque el trabajo amargo nos trajo aquí

arrastrados y metidos como clavos

en palmas y pies desde la horrible

barriga del madre barco destripando

cadenas umbilicales

cortadas

con vinagre sal y herrumbre de sangre marina

flagelados (119).

8 "Un poeta de protesta y revolución” (Traducción propia). 
La primera edición de Nativity es de 1988 y fue publicada por House of Nehesi. La misma casa editorial publicó en 2010 la versión trilingüe de la que proviene la cita anterior. En la portada aparece el título en inglés, francés y castellano -Nativity/Nativité/Natividad-, idiomas en los que se presentan también la introducción de Afua Cooper, el glosario y la información sobre el autor. La publicación del poema en estos tres idiomas permite que la obra de Sekou llegue a un importante número de lectores de las distintas subregiones caribeńas, lo que forma parte del proyecto de House of Nehesi de contribuir a la integración de una región fragmentada por una historia colonial que incentivó los vínculos verticales entre las colonias y sus metrópolis europeas, a la vez que obstaculizó activamente los contactos horizontales entre las islas.

Es sumamente interesante conocer el proyecto de House of Nehesi y su impacto en la producción literaria de San Martín y el Caribe. La creación de esta editorial es uno de los hitos fundamentales en el esfuerzo de Sekou por generar las condiciones para la consolidación de un sistema literario en San Martín. Como señala la página web de la editorial: "The book publishing division was founded in 1982 in New York, USA. The foundation was established in 1986 in Philipsburg, St. Martin, Caribbean, as a non-profit/non-governmental organization (NGO)" ("About us") ${ }^{9}$. House of Nehesi le permitió a Sekou, su fundador, publicar sus propios libros e impulsar la creación y publicación de textos literarios en la isla de San Martín. En una primera etapa, se publicaron sobre todo libros de poesía y ficción, pero, con el tiempo, el catálogo se fue ampliando para incorporar textos académicos, ensayísticos y de arte. En sus casi cuarenta años de existencia, la editorial se ha establecido como "un punto de referencia ineludible en lo que se refiere a dar a conocer la producción literaria de la Isla -escrita en lengua inglesa- así como divulgar la obra de importantes intelectuales de la región caribeña, con la modalidad reciente de publicar ediciones bilingües y trilingües" (Rodríguez 137).

La instalación de esta editorial en San Martín produjo un impacto profundo en su vida cultural y literaria, lo que, como señala

9 "La editorial fue fundada en 1982 en Nueva York, Estados Unidos. En 1986, la fundación se estableció en Philipsburg, San Martín, en el Caribe, como una organización no gubernamental sin fines de lucro" (Traducción propia). 
Adekunle, demuestra la importancia que tiene que el Caribe cuente con sus propias editoriales. Desde 2003, la Fundación House of Nehesi organiza -en conjunto con Conscious Lyric Foundation, de la parte norte de la Isla- una Feria del Libro que se realiza anualmente: The St. Martin Book Fair, que juega un papel importante en la integración del territorio isleño, a la vez que dinamiza y conecta la actividad literaria caribeña ("Book Fair"). El que autores consagrados como Kamau Brathwaite y George Lamming hayan publicado sus últimos libros en House of Nehesi es un paso importante en lo que Adekunle denomina como un "proceso de indigenización" (40) de la producción literaria del Caribe. Por primera vez, autores de San Martín y de otros países caribeños están al alcance del público lector de la isla, quienes pueden encontrar sus libros en librerías, algunos supermercados grandes, tiendas y kioscos (Adekunle 43). De este modo, se favorece la formación y consolidación del público lector caribeño, uno de los actores del sistema literario que es fundamental fortalecer para que los y las escritoras caribeñas puedan dedicarse profesionalmente a la literatura.

\section{HURRICANE PROTOCOL}

Una de las frases más citadas de Kamau Brathwaite es "el huracán no ruge en pentámetros" (123), aparecida en su ensayo "Historia de la voz". Brathwaite quiere decir con esto que "no tenemos las sílabas, la inteligencia silábica, para describir el huracán, que es nuestra propia experiencia, mientras que podemos describir la experiencia ajena importada de la caída de la nieve" (121). La imposición de imaginarios y lenguajes europeos a través de la educación colonial es un tema que ha sido ampliamente tratado por la literatura caribeña y la crítica literaria postcolonial, que ha acuñado el concepto de "Daffodil Gap" ["la brecha del narciso"] para dar cuenta de la distancia entre la naturaleza que representan los textos europeos y la que rodea a sus lectores caribeños. Para Brathwaite, es fundamental reconocer que la expresión de experiencias propias requiere de la creación de ritmos y lenguajes distintos a los importados de e impuestos por Europa. Se trata de un doble gesto, en que confluyen la invención con la recuperación. Para desarrollarse plenamente, la actividad artística en el Caribe necesita 
nutrirse de las tradiciones populares desvalorizadas e ignoradas por la educación colonial; la literatura, por su parte, debe ser capaz de conectar con el "nation language"10 [lenguaje-nación].

Como señalé en un apartado anterior, la poética de Sekou ha sido comparada a la de Brathwaite. Con la publicación en 2019 de Hurricane Protocol, este parecido resulta aún más evidente, no solo por la centralidad del fenómeno del huracán, sino por la continua búsqueda de Sekou de lenguajes y ritmos con los que da cuenta de lo que significó su paso por la isla de San Martín. De acuerdo con el propio Sekou, el libro fue escrito durante y después del paso del huracán Irma ("[A] Statement" [una declaración]). Este tocó la isla el 6 de septiembre de 2017 y la primera entrada del poema está datada el 8 del mismo mes, es decir, dos días después. Además, el poema registra el paso del huracán María, que llegó a la isla el 19 de septiembre y se sumó a los destrozos causados por el Irma. Sekou cuenta que este último destruyó el $90 \%$ de las construcciones y el ambiente natural de la isla y dejó a la población sin electricidad ni agua potable (3). El nivel de devastación sufrido se evidencia también en la lentitud de la recuperación: "Many of us are in recovery mode, some too painfully slow, some barely at all, well into $2019 . . . "(5)^{11}$.

Un aspecto destacado por Sekou en su declaración inicial es su interés por explorar, en este poema largo, territorios que por lo general han estado menos presentes en su obra. Esta suele referir a aspectos sociopolíticos e históricos de la vida caribeńa y a expresar el compromiso del autor con las luchas anticoloniales del Caribe y, en particular, con la independencia de su isla. En Hurricane Protocol, el autor se detiene más bien en las dimensiones personales, familiares y comunitarias observadas durante y poco después del paso del huracán. Además, este poemario explora los vínculos entre texto e imagen a través de la incorporación de ilustraciones: se incluyen reproducciones de códigos maya, en un gesto de "tribute to the languages and literatures of the Maya civilization and the indigenas of the Caribbean, from which the word hurricane derives" (6, cursivas en el original) ${ }^{12}$.

10 Para Brathwaite, el lenguaje nación es "el tipo de inglés hablado por la gente traída al Caribe, no el inglés oficial de hoy, sino la lengua de los esclavos y trabajadores, los sirvientes que fueron traídos por los conquistadores" (117-118).

11 "Muchos todavía estamos en proceso de recuperación, algunos de un modo penosamente lento; aún en el 2019 algunos todavía no se recuperan” (Traducción propia).

12 “Tributo a los lenguajes y literaturas de la civilización maya y de los indígenas 
Los dibujos incluidos en el libro pertenecen a las páginas diez y once del Códice de Dresde, modernizados por Lacambalam. Como se sabe, la mayor parte de los códices maya fueron destruidos por los españoles, que consideraron que tenían un carácter demoníaco. Casi todas las entradas de Hurricane Protocol están acompañadas por un dibujo del Códice de Dresde. De este modo, la destrucción causada por los conquistadores y la producida por los huracanes son puestas en paralelo, y ubicadas en una historia de larga duración. Por otra parte, se reconoce también la existencia de una cultura anterior a la conquista que permitía nombrar al huracán con un vocablo propio, de origen caribe. Se establece así un vínculo entre la historia natural y cultural de la región y se releva la importancia de recuperar fuentes y memorias que la violencia de la conquista destruyó, pero que perviven en fragmentos, retazos y posibilidades de nombrar: "And before the mayaimi too once/ there was huracan to name it/ so that though it came first/ movingallovertheplace/ it had to have a name/ to be known for what it is" $(27)^{13}$.

El libro Hurricane Protocol tiene dos partes. La primera corresponde al poema homónimo -"Hurricane Protocol"- y la segunda reúne diez poemas en un apartado titulado "Back Matter[s]", que aborda temas no relacionados con el huracán. "Hurricane Protocol" está compuesto por catorce entradas tituladas con una fecha, como si fuera un diario de vida, pero dedicado al registro de la temporada de huracanes de 2017. El primer día registrado es el 8 de septiembre -es decir, dos días después de la llegada del huracán Irma a San Martín-y el último es el 30 de noviembre de ese ańo. Los poemas van anotando distintos aspectos del paso de los huracanes: la fuerza de los vientos, la lluvia incesante, la destrucción de cerros, colinas, manglares; los techos que vuelan, las ventanas rotas, las pertenencias de diverso tipo flotando en las calles convertidas en río. También dan cuenta del estupor de la gente, del miedo, de los esfuerzos por comunicarse y el aislamiento provocado por la caída de las señales de celulares. Surgen al mismo tiempo imágenes que dan cuenta de una experiencia vivida en conjunto, en que se forjan y refuerzan lazos de comunidad.

del Caribe, de lo que deriva la palabra huracán" (Traducción propia).

13 "Y también antes de los mayaimi/ existía huracán para darle nombre/ así que aunque llegó primero/ moviéndosealrededordetodalaregión/ tenía que tener un nombre/para ser conocido por lo que es" (Traducción propia) 
Al igual que en otros poemas de Sekou, en "Hurricane Protocol" encontramos una diversidad de idiomas y registros. Predomina el uso del inglés, pero también hay entradas escritas en creole de San Martín y versos salpicados de palabras en castellano, holandés y francés. En algunas páginas se imitan sonidos, en otras se combinan sílabas y fragmentos de palabras para dar lugar a neologismos como "malonglongsong/ ahlingehlongahsong" (30), donde reconocemos "long" y "song" que, en conjunto, crean una palabra que refiere a la larga canción del poeta. Finalmente, el poema entronca, en sus dos últimos versos, con la tradición oral de San Martín: "lead ben'/ season en"'14.

La expresión “lead ben'/ story en"” es la frase usada en San Martín para terminar relatos orales ${ }^{15}$. Funciona como una marca de finalización que comunica a la audiencia el término de la historia. De este modo, el poema vincula la experiencia del paso de los huracanes Irma y María en 2017 con la tradición oral de San Martín y sugiere que, por más dura que sea la temporada, siempre tiene un final. El poema se puede leer como una historia que se inicia el 8 de septiembre y termina el 30 de noviembre, pero sus ecos y huellas permanecen más allá. Como señala Sekou en el prefacio al libro, es lenta y penosa la recuperación tras el paso de dos huracanes de categoría 5. En la memoria colectiva de la isla quedarán, muy probablemente, las huellas de ese septiembre de 2017. Con "Hurricane Protocol" Lasana Sekou ofrece a su comunidad, y también a un público lector externo a ella, un conjunto de imágenes y lenguajes que recrean, elaboran y, por momentos, buscan conjurar los estragos que causan los vientos huracanados.

\section{Algunas reflexiones finales}

El cambio climático ha afectado la intensidad y el comportamiento de los huracanes. Debido al alza de la temperatura del océano, se forman cada vez más huracanes de forma simultánea y muchos alcanzan las categorías más altas. En 2017, los huracanes Irma y María alcanzaron categoría 5 y afectaron enormemente a muchas islas del Caribe. Esta región es una de las más vulnerables frente a las amenazas del cambio

14 "Se acaba el hilo/ termina la estación" (Traducción propia).

15 Otra variante de esta fórmula es: "De wire bend, De story end" (Dillard 18). 
climático, a pesar de su "mínima contribución a las emisiones globales de gases de efecto invernadero (GEI)" (Banco Interamericano de Desarrollo). En 2019, Lasana Sekou, poeta de la isla de San Martín, publicó el libro Hurricane Protocol, donde registra su experiencia y la de su comunidad ante el paso de Irma y María. El poema muestra la devastación que dejan estos fenómenos naturales, notablemente agravados por la acción humana en el planeta. Además de comentar este poema, en este ensayo he querido visibilizar la rica y vasta producción poética y el trabajo editorial de Lasana Sekou, que ha actuado como catalizador en la consolidación de un campo literario en San Martín y juega un rol protagónico en los esfuerzos por lograr una integración de las literaturas del Caribe.

Bibliografía

"About Us". http://houseofnehesipublish.com/sxm/about-us/. Página visitada el 15 de septiembre de 2020.

Adekunle, Fabian. Salted Tongues. Modern Literature in St. Martin. St. Martin, House of Nehesi Publishers, 2003.

Banco Interamericano de Desarrollo. "Cambio climático en los pequeños estados insulares del Caribe”. Banco Interamericano de Desarrollo. 09 de enero de 2020. 30 de septiembre de 2020. Web. https://www.iadb.org/es/ove/cambio-climatico-en-los-pequenos-estados-insulares-del-caribe

Barnet, Miguel. "Editorial". Catauro. Revista cubana de antropología, año 12, $\mathrm{N}^{\circ} 22,2010$, p. 4.

"Book Fair". House of Nehesi. 15 de septiembre de 2020. http://houseofnehesipublish.com/sxm/st-martin-book-fair/

Brathwaite, Kamau. "Historia de la voz. El desarrollo del lenguaje nación en la poesía caribeña anglófona”. La unidad submarina. Ensayos caribeños. Florencia Bonfiglio (ed.), Buenos Aires, Ediciones Katatay, 2010, pp. 115-167.

Cooper, Afua. "Introduction”. Nativity. Nativité. Natividad. Lasana Sekou, Philipsburg, House of Nehesi Publishers, 2010. 
Dillard, J. L. "Some Variants in Concluding Tags in Antillean Folk Tales”. Caribbean Studies, vol. 2, N 3, 1962, pp. 16-25.

Fergus, Howard. "Introduction". Salted Tongues. Modern Literature in St. Martin. Fabian Badejo, St. Martin, House of Nehesi Publishers, 2003.

Rodríguez, Emilio Jorge. El Caribe literario. Trazados de convivencia. La Habana, Editorial Arte y Literatura, 2011.

Sekou, Lasana M. "ADN”. Hurricane Protocol. Philipsburg, House of Nehesi Publishers, 2019. . Hurricane Protocol. Philipsburg, House of Nehesi Publishers, 2019. Nativity. Nativité. Natividad. Philipsburg, House of Nehesi Publishers, 2010. "Quimbé" (Callaloo), Caribbean Literature from Suriname, The Netherlands Antilles, Aruba, and The Netherlands: A Special Issue, vol. 21, N 3, 1998, p. 674.

Vega, Ana Lydia. "Encancaranublado". Encancaranublado y otros cuentos de naufragio. Puerto Rico, Editorial Antillana, 1983. 